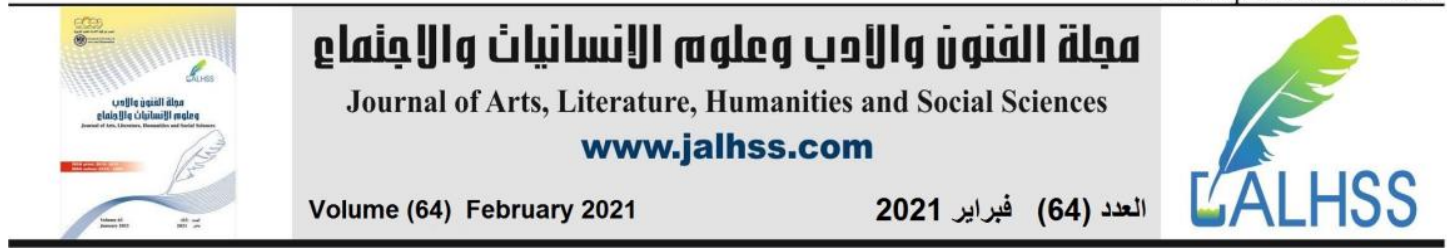

\title{
Motivation for WhatsApp use among Students at the University of Jeddah
}

\author{
Lowai G. Abed \\ Assistant Professor \\ University of Jeddah, College of Communication and Media, Department of \\ Communication and Public Relations, Jeddah, Saudi Arabia \\ Email: 04101097@uj.edu.sa
}

\begin{abstract}
As the twenty-first century has progressed, the processes of learning and imparting knowledge have increasingly followed a modern, digitized approach that makes use of modern communications. The recent and ongoing development of online communication platforms now allows millions of users to communicate with each other quickly and easily. WhatsApp, which is very popular with Saudi Arabian college students, is a social networking site that is primarily used on smartphones as an application for instant messaging. The research presented here explores the motivations that drive Saudi Arabian college students to use WhatsApp. Moreover, this research sheds light on the advantages and disadvantages of WhatsApp and elucidates the students' perceptions of how WhatsApp use impacts the quality of their university education. This study is of an exploratory, qualitative design and the study sample comprised 23 undergraduate students from the University of Jeddah. An online questionnaire, containing open-ended questions, was used to identify the key factors that motivate students to use WhatsApp. The findings reveal that the simplicity and popularity of WhatsApp are the most significant factors in students' decision to use it. The key advantages of using WhatsApp were found to be its fast speed and ease/efficiency of reaching recipients. Students indicated that they mainly used the app to establish or maintain contact with classmates and professors, and that they believed the use of WhatsApp had a positive effect on the quality of their education. However, while the app is clearly popular, some students reported the selfdestructive nature of some WhatsApp messages as an important disadvantage.
\end{abstract}

Keywords: WhatsApp, Motivation, Education, Communication. 


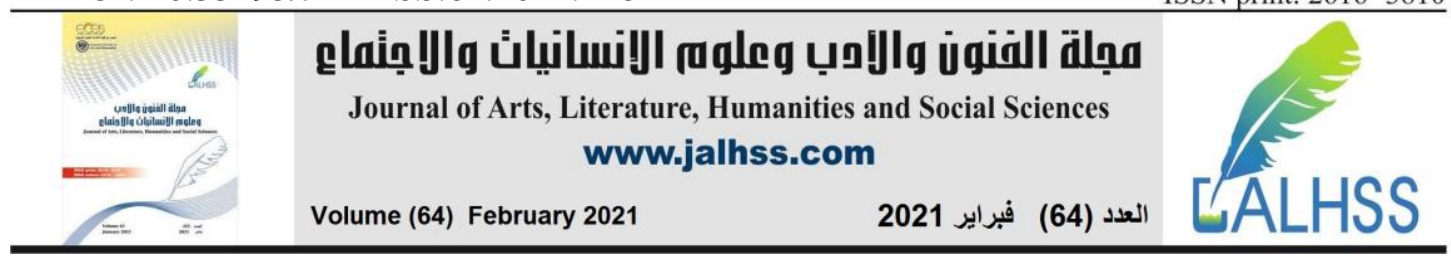

Introduction: The Use of Social Networks for Communication Purposes

Following development of the internet and advances in cell phone technology during the first decades of the twenty-first century, people of all ages have become used to fast and convenient forms of communication. Thus, digital messaging services such as BlackBerry Messaging (BBM) and WhatsApp messaging have become increasingly popular. WhatsApp is one of the several mobile instant messaging (MIM) applications currently available, and since its public launch in 2009 has become hugely popular in many countries around the world. WhatsApp has been identified as the most popular messaging app in more than 109 countries. According to the statistics given in a 2016 research report (Rosenberg, 2016), WhatsApp has gained a staggering number of users, with one in every seven people on the planet using the application. More specifically, WhatsApp is very popular among the citizens of Saudi Arabia: statistics provided by Global Media Insight (Global Media Insight, 2020) show that more than 20 million people in Saudi Arabia use WhatsApp every day. And while instant messaging is popular with many demographics, the use of instant messaging services has become commonplace among undergraduate students worldwide (Lenhart, 2007).

WhatsApp may usefully be considered as a social network that facilitates rapid access to, and sharing of, information. It is a simple platform, that can be used easily by individuals of all ages and backgrounds - anybody with a smartphone and an active internet connection can use WhatsApp. Additionally, it is very cheap to use; costs are eliminated or kept low because all messages that are sent on WhatsApp travel via an internet data connection rather than a cellphone network, and thus do not incur mobile network charges. WhatsApp supports various message types and formats, including text messages, images, audio and/or video files (Alsaleem, 2013). When using WhatsApp, individuals can communicate one-on-one or in closed, members-only groups.

The ability of WhatsApp to generate communication that imitates in-person conversations, and its capacity to facilitate immediate communication (for example, in the form of synchronous messages between group members), have been highlighted as key factors contributing to its success (Malka, Ariel, \& Avida, 2015). The app has also been identified as having the potential to help individuals to develop and maintain personal relationships and social group membership (Church \& de Oliveira, 2013).

WhatsApp, as a prominent MIM application, has found a place in the context of higher education, where it is used in numerous ways and to achieve diverse educational goals. For instance, Gachago, Strydom, Hanekom, Simons, and Walters (2015) have argued that WhatsApp can be used in higher education not merely as a quick and easy means of communication, but as an effective way to achieve other underlying objectives of education, as well. For example, WhatsApp meets the need 


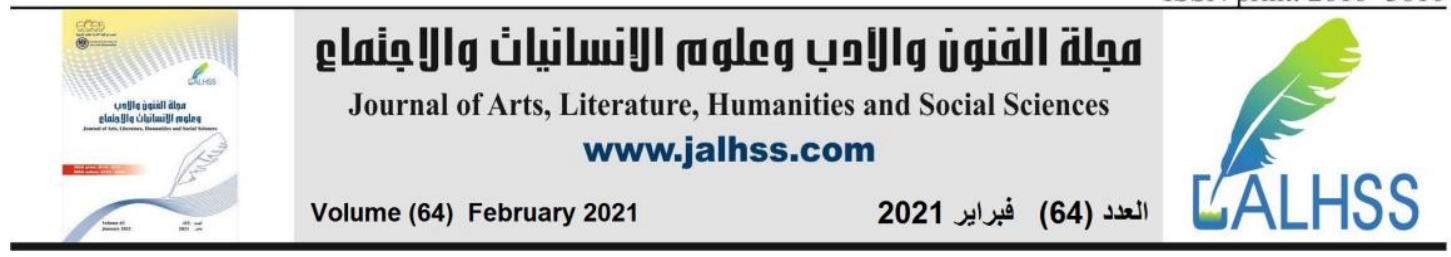

to create immediate connections, encourage reflection, and facilitate coordination in both formal and informal learning processes. Chipunza (2013) found that WhatsApp is a useful electronic tool to facilitate the quick and easy sharing of information among university students on a range of subjects related to their courses of study.

The original research presented in this paper was carried out to investigate and identify the factors that motivated students at a Saudi Arabian public university to use WhatsApp, since this topic has yet to be explored qualitatively in the Saudi Arabian context. To achieve this, a qualitative methodology was used, whereby 23 male students - who attended the University of Jeddah and were regular WhatsApp users were asked to complete an online questionnaire with six open-ended questions. Analysis of their responses identified a number of factors as motivating the students' use of WhatsApp, and several advantages and disadvantages of WhatsApp use in educational setting emerged. The results also indicated that WhatsApp had positive effects on the students' university experiences.

\section{Literature Review}

Since 2009 or thereabouts, a substantial and diverse range of digital communication channels has emerged; this category includes relatively direct means of communication, such as SMS and email, and means of communication embedded within a wider social media/broadcasting application such as Twitter, Facebook Messenger, and WhatsApp. Despite their various similarities, all of these channels have their own distinctive features, and these affect the likelihood that, and extent to which, students will use them - or not (Calvo, Abilo \& Iglesias, 2014).

Social networking sites (SNSs) have been defined as "web-based services that allow individuals to (1) construct a public or semi-public profile within a bounded system, (2) articulate a list of other users with whom they share a connection, and (3) view and traverse their list of connections and those made by others within the system" (Boyd \& Ellison, 2007, p. 211). Their related products and applications - including WhatsApp - are popular among students pursuing higher education in universities and colleges around the world, with many students claiming to use multiple SNSs quite frequently. This phenomenon has been reflected in the results of numerous research studies, based on data gathered from multiple universities. For instance, Bsharah, Gasaymeh, and Abdelrahman (2014) found that $92.6 \%$ of 282 university students who participated in a study conducted in a Jordanian university reported using Facebook. Hamade (2013) found that $89 \%$ of a total of 300 university students in Kuwait who participated in a study reported that they used Twitter. In a large-scale study, Karpinski, Kirschner, Ozer, Mellott, and Ochwo (2013) discovered that all (100\%) of the 875 responding students from universities in the United States and Europe reported using various types of SNS, and according to Vorderer, Krömer \& Schneider (2016) a substantial majority of students commonly used their smartphones to access their preferred SNSs, a habit that allowed them to quickly and easily use each SNSs at any time and from any location. According to some sources (Raza, Qazi \& Umer, 


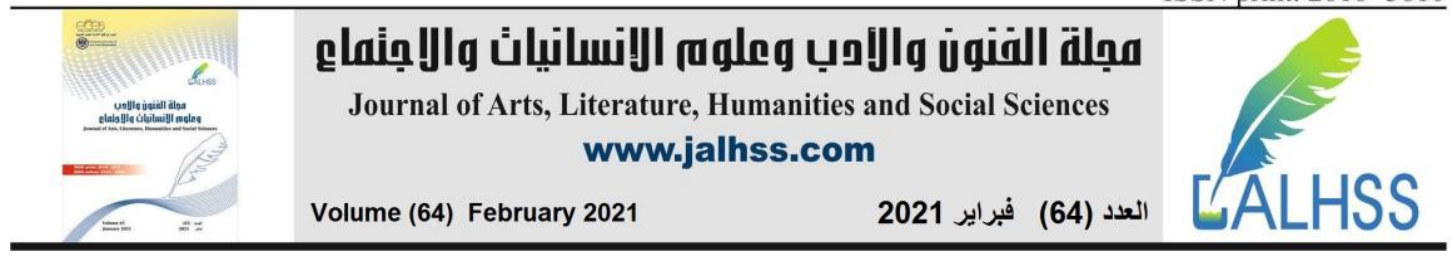

2017; Eid \& Al-Jabri, 2016) SNSs are used for multiple purposes, which range from direct communication to the exchange of media and as a source of entertainment.

Prior research has explored the various types of instant messaging (IM) services from a range of perspectives. For instance, Smit (2012) explored the use of IM platforms in communications between students and faculty members and found that such interactions had the potential to enhance learning. Moreover, Cifuentes and Lents (2011) found that IM messaging between faculty members and students could help students to become more active in their own learning and may encourage interpersonal interactions between faculty members and students; other researchers have found that IM messaging promotes informal communication between students and staff (Cifuentes \& Lents, 2011; Smit, 2012).

Doering et al. (2008) and Sweeny (2010) both found that the use of IM for communication between students and staff offered students a greater sense of belonging and community membership, while Doering et al. (2008) emphasized the capacity of IM platform use to break down social barriers between teachers and students. Sweeny (2010) also found that students often tried to impress their classmates and so took assignments more seriously around their peers, thus the relatively public nature of IM communication may motivate students to produce better work and/or work harder than might otherwise have been the case.

Findings from prior studies, such as Malecela, (2016), Deshen, Buchnik \& Brochson (2014), and Rambe and Bere (2013), that have investigated the use of social networks and IM platforms in teaching contexts have shown that these tools can convey many advantages for the processes of education. For example, such digital means of communication can promote collaborative learning, informal communication, and active class participation. Moreover, the fact that the nature of digital communications makes them appropriate for use at any time of day, and that the mobile nature of many IM platforms permits students to learn in any place, at any time, greatly enhances their flexibility and application. The increasing popularity of smartphones, along with their many formats and extensive availability, has also prompted many students to turn to WhatsApp, enhancing its popularity within this demographic.

For instance, Malecela (2016) examined how students at a university in Malaysia perceived the use of WhatsApp as a learning tool. That study employed a qualitative research design, whereby interviews were conducted with a selected group of students. The interviewer asked a series of open-ended questions, which allowed the students to freely express their views and thoughts on the subject. According to the results, these students believed that WhatsApp was of great help in their learning activities and it conveyed benefits by facilitating quick and effective two-way communication with other students and the instructors, encouraging a better learning experience with greater collaboration, more scope for discussion, and easier access to and sharing of educational information. However, the responding students in Malecela's study also noted that the use of WhatsApp as a learning tool had certain 


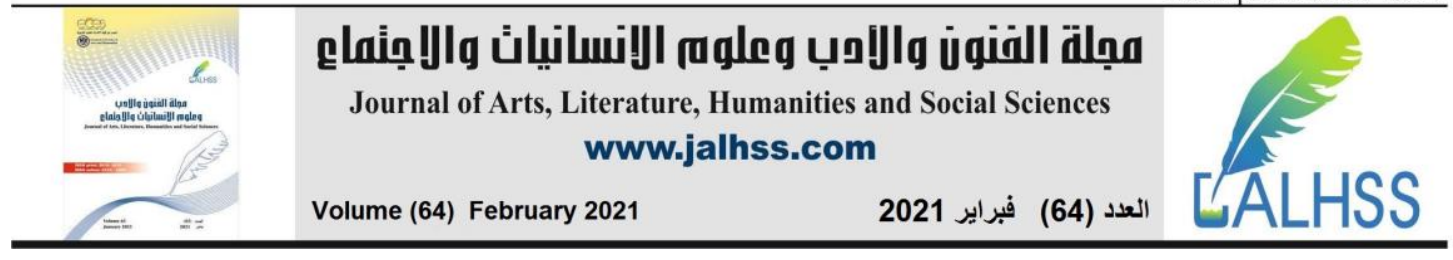

limitations. For example, it did not involve face-to-face communication, and could be time consuming because there was generally a time lag whereby it took a while for the receiver to see and/or respond to the message. Students also mentioned that WhatsApp use carried a risk of miscommunication and of communication being constrained by the rules of phone etiquette. Further, WhatsApp is dependent on Wi-Fi connections (the presence and stability of which cannot always be guaranteed) and its effectiveness as a tool for quick and easy two-way communication may be hindered for individuals who keep their phones on silent mode.

Deshen, Buchnik \& Brochson (2014) looked at the use of class WhatsApp groups and found that these may be more than merely useful as tools for communication between staff and/or students. They found that such groups were also widely used to nurture and encourage a social atmosphere in class, by providing a platform for students to converse with and get to know their peers and teachers while simultaneously encouraging collaboration and dialogue among members of the same class, which in turn functions as an informal means of imparting knowledge.

In addition, when used in conjunction with distance learning platforms, WhatsApp enables the quick and easy sharing of documents and study content in real time. Another benefit is the opportunity that WhatsApp gives teachers to familiarize themselves with the students and to establish high quality student-teacher relationships based on trust and mutual understanding, which is proven to have a positive influence on student discourse. This advantage is particularly relevant and useful in cases where students use online learning platforms, since these permit at best only limited in-person meetings between teachers and students, and often none at all.

Even in strictly academic terms, using WhatsApp in the context of education can provide multiple benefits. WhatsApp can make a tangible contribution to learning by allowing the student to request help and/or information from their tutor regardless of the location of each, and any time zones involved. This is particularly helpful where learning communities are dispersed and/or with remote learning platforms. That same independence of time and place makes WhatsApp very useful as a platform for new learning methodologies, especially those which cannot be constrained within the four walls of the classroom, and wherever quick access to (online or shared) study materials is required.

However, the use of WhatsApp as a tool for communication and learning within academic contexts does have some drawbacks, the primary and most obvious of these being the fact that not all students have access to a smartphone, which is required for practical use of the app. Other issues include the fact that WhatsApp groups and conversations can quickly generate an overwhelming volume of messages, many of which may be irrelevant to most readers, and the need to deal with improper language, particularly in large WhatsApp groups that may be difficult to control. Finally, students may have high expectations of an educational WhatsApp group - particularly that the teacher will answer their questions quickly, perfectly and effortlessly - and 


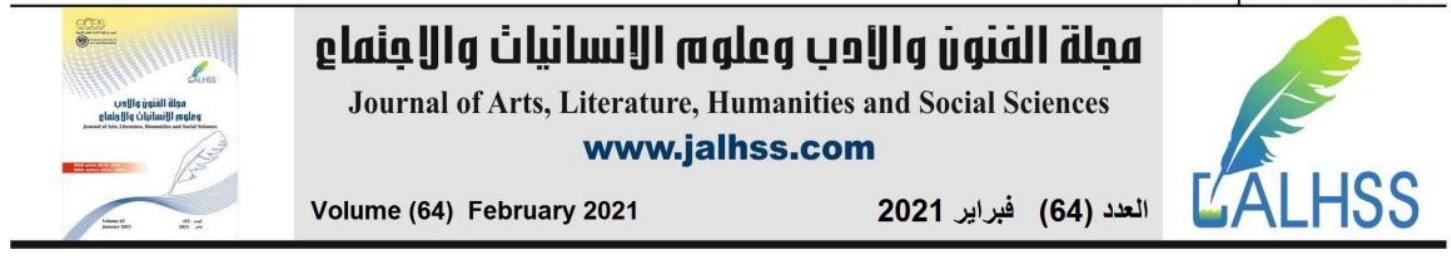

the reality, with its inevitable delays, misunderstandings and responses that may be perceived as sluggish or otherwise unsatisfactory, might cause the students to feel a sense of neglect or frustration, and the teachers to feel overwhelmed by the sheer volume and constant stream of messages.

Nonetheless, there is plenty of evidence that WhatsApp can be useful in academic settings. In a study carried out by Rambe and Bere (2013), students attending a university class in South Africa gave positive feedback about their use of WhatsApp, reporting that it allowed them to communicate quickly and easily with their teachers and classmates. These students also reported that WhatsApp use created an informal environment, conducive to substantial, in-depth discussions about relevant issues, and that this helped students to learn in a fun, intimate, and authentic manner. Lauricella and Kay (2013) explored students' experiences of and opinions regarding the use of text messaging and IM services. They focused particularly on the frequency of use, comfort level, usefulness, reasons for using messaging services, and how peer-to-peer interactions differed from peer-to-instructor interactions. Their findings were that students felt comfortable sending text and instant messages and the researchers concluded that text and instant messaging services can play a significant role in improving communications between students and their peers/faculty members in university settings.

Church and Oliveira (2013) compared the use of WhatsApp with that of traditional SMS services. They investigated the motivations and perceptions that drove people's use of the two messaging forms, and of the additional services offered by WhatsApp. In this study, two data collection tools were used - interviews and a large-scale survey. The findings identified several factors that affected the ways in which the studied individuals communicated using these services. Cost was found to have a significant effect on the frequency of use, and social influence emerged as a major motivation for people to use WhatsApp. WhatsApp messages are, in essence, informal and conversational. This contrasts with traditional SMS services, which are often considered to be more private, formal, and reliable. The results thus indicated that the two technologies cannot be considered interchangeable.

In general, the research indicates that modern communication habits are greatly influenced by changes in mobile technologies. The previous research referred to allows us to understand why individuals have increasingly turned to WhatsApp messaging instead of traditional SMS texting, and the extent to which students feel comfortable using WhatsApp for educational purposes.

There are many reasons for the decisions of teachers, professors, and students to make WhatsApp part of the teaching/learning process. In this context, Abaido \& El-Messiry (2016) employed the uses and gratifications approach to understand user motivations, and social constructivism theory to investigate how students develop and build knowledge through personal interactions. Their findings highlighted a growing need for innovative interventions in education, in order to create a more stimulating 

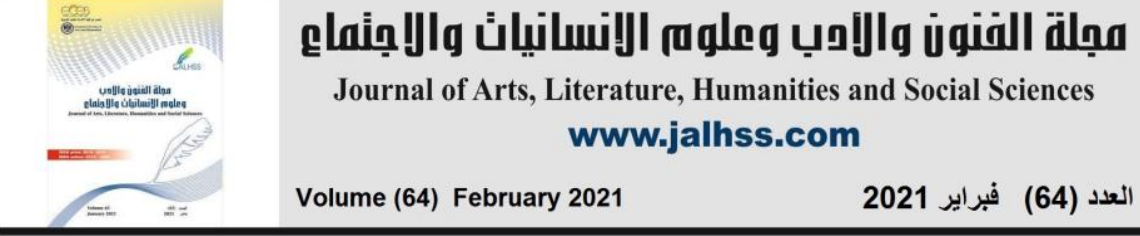

classroom setting (Abaido \& El-Messiry, 2016). Teachers and universities may wish to take advantage of these findings to optimize their classroom settings and to positively influence the learning behaviors of students.

Another study explored students' education-related use of WhatsApp and found that the app had become the preferred method of communication. Many students highlighted the importance of handling emergency information, managing crises, or accessing other urgent information (Jin, Liu \& Austin, 2014). In other research findings by van Rensburg, Conradie \& Dondolo (2017), the majority of participants believed that WhatsApp was effective and beneficial for use in educational settings.

This literature review has shown that multiple studies have identified WhatsApp as having several features that can enhance the learning and contextual experiences of university students in various parts of the world. However, most of these studies have been quantitative in nature. The present study, however, has been conducted using a qualitative approach, in order to obtain rich and meaningful data pertaining to the factors that drive Saudi university students to use WhatsApp, and the advantages and disadvantages of using the application. The current research has also been designed and conducted to understand students' opinions regarding the extent to which WhatsApp has influenced the quality of their university education and experience.

\section{Research Questions and Objectives}

Considering the information given above, the research questions that this study is designed to answer are:

RQ 1 What are the factors that drive students in Saudi Arabia to use WhatsApp?

RQ 2 What are the advantages and disadvantages of using WhatsApp in a university setting in Saudi Arabia, based on students' opinions?

RQ 3 Do students generally believe that the use of WhatsApp impacts the quality of university education?

The current study has three primary objectives. These are to identify the factors that lead students to use WhatsApp, and to ascertain why they prefer to use WhatsApp rather than other types of digital communication. The second objective is to identify what students believe to be the advantages and disadvantages of using WhatsApp. The third objective is to understand how WhatsApp impacts students' perceptions of the quality of their university education.

Thus, the objectives may be formally stated as follows:

Objective 1 To identify the factors driving students in Saudi Arabia to use WhatsApp. 


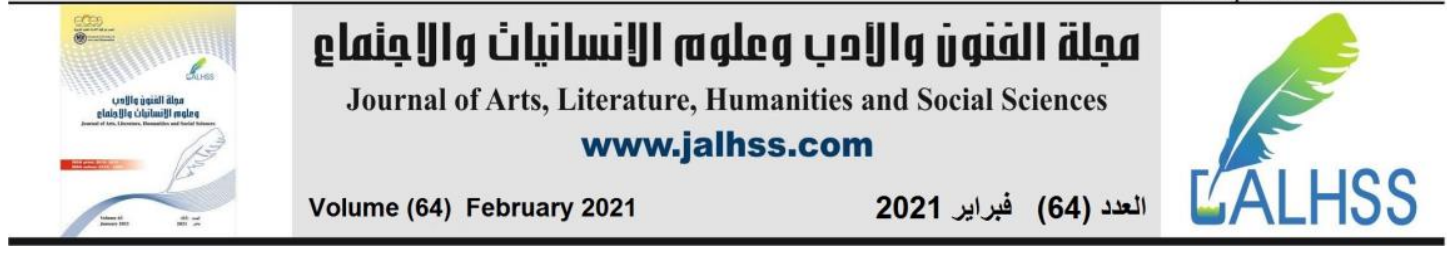

Objective 2 To identify the pros and cons of using WhatsApp, according to the students.

Objective 3 To understand students' perceptions of how WhatsApp impacts the quality of their education.

\section{Methodology}

\section{Instrument}

The aims of the present research are to investigate and identify the factors motivating Saudi Arabian students to use WhatsApp. Thus, a qualitative research approach has been adopted. This approach was selected because the majority of existing studies investigating the uses and applications of WhatsApp in Saudi Arabian universities for example, the research carried out by Reeves \& Alkhalaf, Amasha 2019 and Khatun \& Al-Dhlan (2017) - used quantitative approaches. Thus, in the present study, participants were given the opportunity to express their opinions about the app. They were asked to complete a questionnaire that contained six open-ended questions, and this generated the textual data that was required for analysis, which in turn answered the study questions and met its objectives. The questionnaire is given as Appendix 1 to this paper.

The questionnaire was administered online, to a sample of students attending a course in communication theory at the University of Jeddah. The first section of the questionnaire contained questions pertaining to students' personal and academic lives. The second section of the questionnaire comprised six open-ended questions, all pertaining to their use of WhatsApp and their opinion of it. The key purpose of using the questionnaire was to gain a profound insight into students' opinions and perceptions of using WhatsApp in educational settings.

\section{Study Participants}

A total of 23 respondents took part in the present study, all of whom were male firstyear students of digital media at the University of Jeddah. Their ages ranged from19 to 21 years.

\section{Data Analysis and Results}

As described, the questionnaire contained six open-ended questions, the purpose of which was to give the participants context and opportunity to express their relevant opinions. In the event, respondents gave short, precise answers. These, and the related analysis, are given below. 


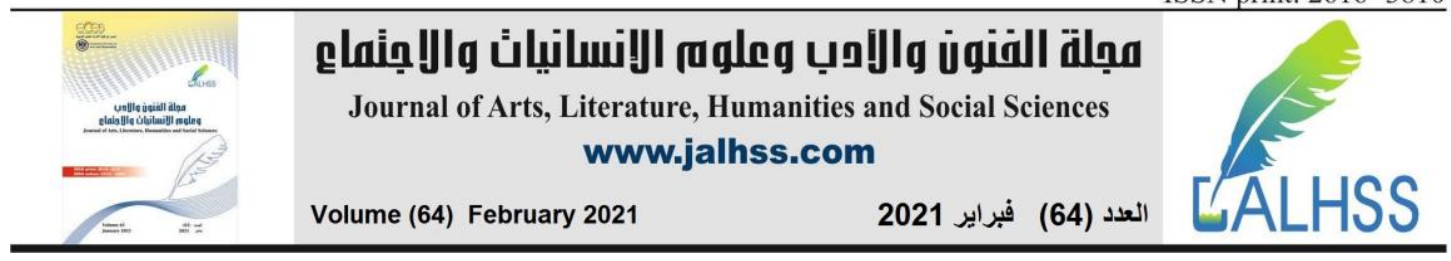

\section{Factors driving Saudi Arabian students to use WhatsApp}

Three items in the questionnaire were designed to explore the respondents' motivations for using WhatsApp and are thus particularly relevant to the first research question: What are the factors that drive students in Saudi Arabia to use WhatsApp?

The first question asked: "Do you use WhatsApp for university affairs? If yes, what exactly do you use it for?" The second asked: "Do you use WhatsApp more than other digital communication methods (such as emails) when communicating with classmates and professors, etc. at university? If yes, please indicate the reasons for which you prefer to use it rather than other electronic communication channels." And in question three, students were asked to indicate how widespread they considered the use of WhatsApp to be amongst university students for education-related communication and other purposes.

The students had broadly similar experiences of and opinions about WhatsApp, and so their responses were consistent. In response to question one, $\sim 53 \%$ of the participants reported that WhatsApp was their primary means of communicating with university lecturers, professors, and other staff. Eighteen percent of students mentioned that they used WhatsApp groups with their classmates, while other participants highlighted the fact that WhatsApp allowed them to obtain information regarding lecture schedules and examination dates. Regarding question two, all of the participants stated that they used WhatsApp more than they used other means of electronic communication due to its simple and convenient features -also, their instructors used WhatsApp to distribute files and assignments. When asked how widespread the use of WhatsApp was in their university, most participants indicated that WhatsApp was very popular.

\section{Advantages and Disadvantages of Using WhatsApp}

The second research question (RQ2) for the current study is, "What are the advantages and disadvantages of using WhatsApp in a university setting in Saudi Arabia, based on students' opinions?" Two of the survey questions addressed this directly. Students were asked to identify the pros and cons of using WhatsApp. One question was: "In your opinion, what are the advantages of using WhatsApp compared to other means of electronic communication in your communication with your colleagues, students, professors, etc. at the university?" Another question asked: "In your opinion, what are the negative effects resulting from your use of WhatsApp that have impacted your learning process at the university?

The findings revealed that the simplicity of using WhatsApp was a key advantage, with every participant describing WhatsApp as quick and simple to use. Several participants said they appreciated the fact that, when using WhatsApp, they could tell whether a message had reached the recipient and whether it had been read. Additionally, all respondents stated that many university students used WhatsApp. 


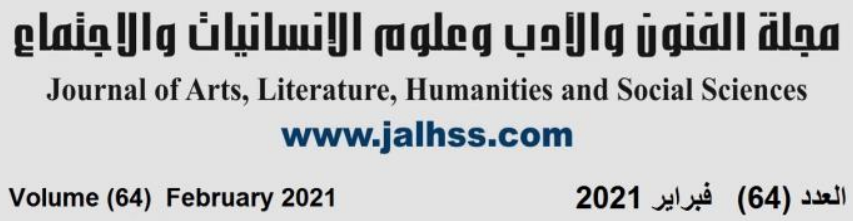

Several other benefits were also highlighted; some said that the application helped individuals to make new friends, and that it was quicker and easier to use than email when communicating with others at the university. WhatsApp delivers messages very quickly, and recipients typically see their messages instantly - these were also cited as benefits. Additionally, WhatsApp was used to remind students of assignment deadlines and examination dates. Participants also reported that they found it easier to send file attachments via WhatsApp than through other digital communication channels.

Notably, although $\sim 27 \%$ of the respondents stated that they could not think of any disadvantages to using WhatsApp, the remainder highlighted several. The disadvantages described included the posting of too many repeated questions, too many messages that drew attention away from important information, unnecessary chatting between group members, confusing messages, use of the app for social rather than educational purposes, a lack of privacy, the sharing of false or incorrect news, the sending of messages to the wrong person/people and a sense of annoyance with the app generally.

\section{The Extent to which Students Believe that WhatsApp Impacts the Quality of their University Education}

The third research question asks, Do students generally believe that the use of WhatsApp impacts the quality of university education?, and respondents were asked about this directly. One participant expressed the view that "it has no effect", but most of the other respondents stated that the use of the application improved their education by motivating them to learn and making them more actively involved in their studies. For instance, one participant felt that "WhatsApp is extremely effective", while another described the app in glowing terms on the grounds that it was very easy for both students and professors to use. One participant stated that WhatsApp motivated students to learn and encouraged them to make new friends. Just one participant gave a neutral response, suggesting that the effectiveness of WhatsApp in this context may depend on the individual's use and attributes.

\section{Discussion}

The present research explored the motivation underlying Saudi Arabian university students' use of WhatsApp. It explored and analyzed students' perceptions of the advantages and disadvantages of the app and examined the extent to which students believe that WhatsApp can affect the quality of their education. The findings revealed that participants were very comfortable with using WhatsApp for educational purposes, primarily because it is simple to use. Compared with other digital communication methods, respondents perceived WhatsApp as being the most popular amongst university students. This is in line with the findings of Gon and Rawekar (2017), who also found that WhatsApp was considered easy to use and very popular among university students and instructors. 


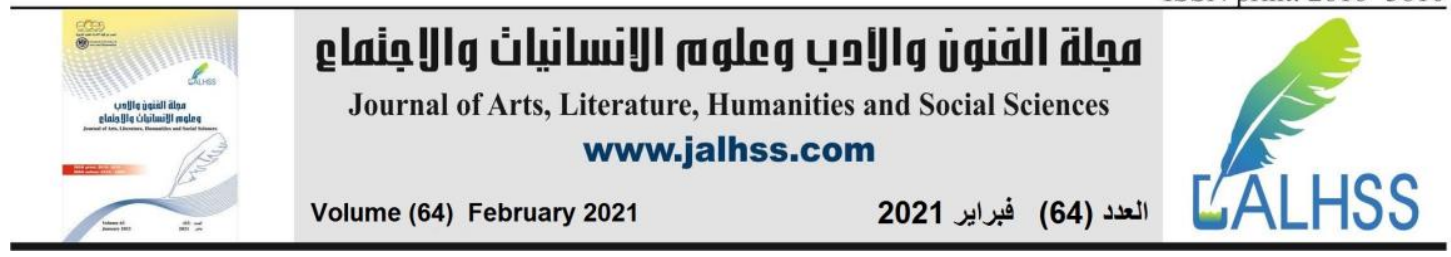

With regard to the advantages and disadvantages of using WhatsApp for educational purposes, many advantages and few disadvantages were highlighted by the students. The advantages included ease of use and popularity amongst students and their instructors. Respondents perceived WhatsApp to be a speedy channel of communication, allowing students to contact their instructors quickly. A key technical advantage identified by the students was that, when using WhatsApp, links to study materials could be shared very easily with others - this is often not the case when using other technologies. Moreover, when study materials are shared via WhatsApp, everyone in the group concerned receives the message, making this an easy and efficient way to access and keep track of study materials. This is in line with the results of a study by Barry, Murphy, and Drew (2014), who discovered that students used WhatsApp to check lecture schedules and examination dates. It is also consistent with the findings of research by Bouhnik and Deshen (2014), which revealed that key factors motivating WhatsApp use included its low cost, privacy, and ease of use. They also found that lecturer availability was another key factor driving the use of WhatsApp, which is supported by the results of a study from Gon and Rawekar (2017). The latter researchers concluded that, when using WhatsApp, learning could take place at any time.

However, several technical disadvantages to WhatsApp use were revealed in the present research. This included message flooding, which was also highlighted in research performed by Gon and Rawekar (2017). However, students in the current study reported that using WhatsApp for educational and communication purposes improved the quality of their education. This is supported by Barry, Murphy, and Drew (2014), who concluded that WhatsApp use significantly enhanced student engagement and ultimately improved learning outcomes.

\section{Conclusions}

The present research has identified several educational and technical benefits that arise from using WhatsApp in university settings, and these have made the application incredibly popular amongst Saudi Arabian university students. It is apparent that WhatsApp has several advantages over other digital communication methods when used in education. These benefits include ease of use, ease of access, and high efficiency. WhatsApp is now the most popular IM tool used by college students in Saudi Arabia, who believe that the application is extremely convenient and enhances their educational experiences. Moreover, students also use WhatsApp for purposes unrelated to their university studies, thus the application helps them to communicate in all aspects of their lives.

Several advantages attached to WhatsApp in educational settings were highlighted in the present study, including ease of use and efficiency. Also, it became apparent that almost everyone in the university used the app, including students and professors. This investigation identified several technical advantages of WhatsApp, including its speed, capacity and suitability for the sharing of learning materials, and the ability of 


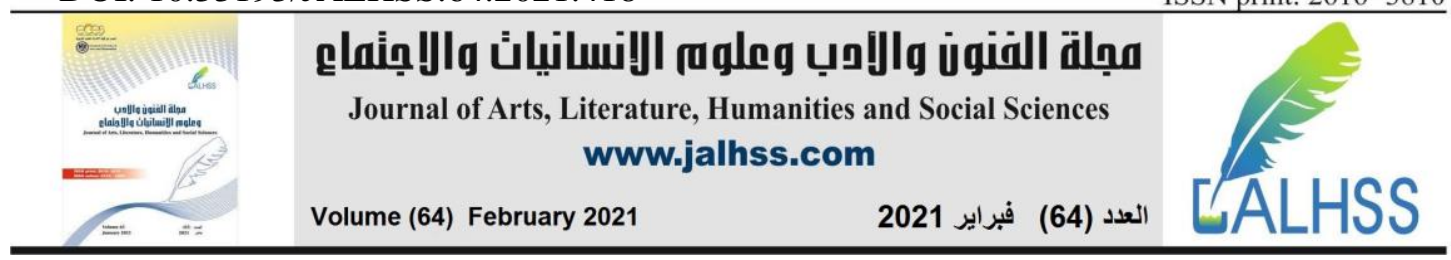

the sender to find out when a message had been received and read by the recipient. However, a few disadvantages were also revealed, including the self-destructing nature of some messages and the tendency of some users to develop a general sense of annoyance with the app. In general, however, it seems reasonable to assert that if the popularity of WhatsApp continues to grow amongst students and instructors, further research will be required to explore the properties of WhatsApp in terms of how these may be effectively incorporated into education processes to achieve pedagogical goals. A range of qualitative research methodologies will be required to achieve this and to enable researchers to draw theoretical and practical conclusions. The present study has focused on university students, and future studies may wish to explore the opinions of university instructors, too.

\section{References}

1. Abaido, G., \& El-Messiry, H. (2016). Efficiency of WhatsApp as a means of disseminating educational information. IT \& Knowledge Excellence, 5(2), 1-5. https://www.researchgate.net/publication/336835700_Efficiency_of_Whats_App_as a_means_of_disseminating_educational_information

2. Alsaleem, B. I. A. (2013). The effect of "WhatsApp" electronic dialogue journaling on improving writing vocabulary word choice and voice of EFL undergraduate Saudi students. Arab World English Journal,4(3), 213-225. https://www.awej.org/images/AllIssues/Volume4/Volume4Number3Sept2013/18.pdf 3. Barry, S., Murphy, K., \& Drew, S. (2015). From deconstructive misalignment to constructive alignment: Exploring student uses of mobile technologies in university classrooms. Computers \& Education, 81, 202-210. https://www.sciencedirect.com/science/article/abs/pii/S0360131514002346?via\%3Di $\underline{\text { hub }}$

4. Bsharah, M., Gasaymeh, A. M., \& Abdelrahman, M. B. (2014). The relationship between the use of social networking wites (SNS) and perceived level of social intelligence among Jordanian university students: The case of Facebook. International Journal of Psychological Studies, 6(3), 1. https://www.academia.edu/34821311/The relationship_between the use_of_social_n etworking_sites_SNS_and_perceived_level_of_social_intelligence_among_Jordanian _university_students_The_case_of_Facebook

5. Bouhnik, D., \& Deshen, M. (2014). WhatsApp goes to school: Mobile instant messaging between teachers and students. Journal of Information Technology Education: $\quad$ Research, 13(1),

217-231. http://www.jite.org/documents/Vol13/JITEv13ResearchP217-231Bouhnik0601.pdf

6. Boyd, D. M., \& Ellison, N. B. (2007). Social network sites: Definition, history, and scholarship. Journal of Computer-Mediated Communication, 13(1), 210-230. https://academic.oup.com/jcmc/article/13/1/210/4583062

7. Calvo, R., Arbiol, A., \& Iglesias, A. (2014). Are all chats suitable for learning purposes? A study of the required characteristics. Procedia Computer Science, 27, 251-260. https://www.sciencedirect.com/science/article/pii/S1877050914000301 

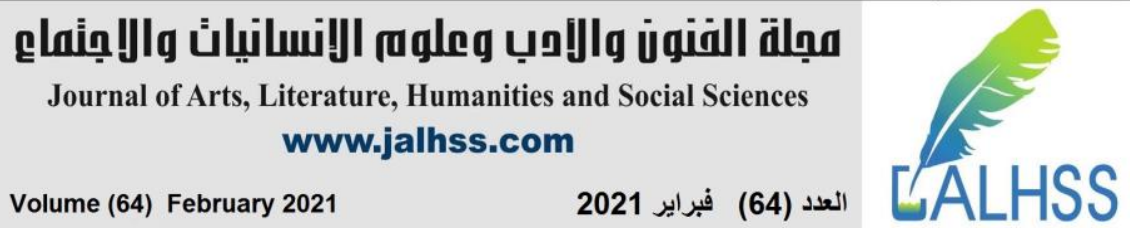

8. Deshen, M., Buchnik, D. \& Brochson, S. (2014). Bar-Ilan University. Available at: http://meital.iucc.ac.il/ conf2014/Meital_Conference_BL14_part_1.pdf

9. Gachago, D., Strydom, S., Hanekom, P., Simons, S., \& Walters, S. (2015). Crossing boundaries: lecturers' perspectives on the use of WhatsApp to support teaching and learning in higher education. Progressio, 37(1), 172-187. https://www.researchgate.net/publication/290339914_Crossing_boundaries_lecturers' _perspectives_on_the_use_of_WhatsApp_to_support_teaching_and_learning_in_Hig her_Education

10. Chipunza, P. R. C. (2013). Using mobile devices to leverage student access to collaboratively generated resources: A case of WhatsApp instant messaging at a South African university. In International Conference on Advanced Information and Communication Technology for Education ICAICTE. https://www.atlantispress.com/proceedings/icaicte-13/8846

11. Church, K., \& de Oliveira, R. (2013). What's up with WhatsApp? Comparing mobile instant messaging behaviors with traditional SMS. Paper presented at the 15th International Conference on Human-Computer Interaction with Mobile Devices and Services (pp. 352-361). https://www.ic.unicamp.br/ oliveira/doc/MHCI2013 Whatsup-with-whatsapp.pdf

12. Cifuentes, O. E., \& Lents, N. H. (2011). Increasing student-teacher interactions at an urban commuter campus through instant messaging and online office hours. Electronic Journal of Science Education, 14(1). https://www.researchgate.net/publication/268029423_Increasing_Student-

Teacher_Interactions_at_an_Urban_Commuter_Campus_through_Instant_Messaging and_Online_Office_Hours

13. Doering, A., Lewis, C., Veletsianos, G., \& Nichols-Besel, K. (2008). Preservice teachers' perceptions of instant messaging in two educational contexts. Journal of $\begin{array}{llll}\text { Computing in } \quad \text { Teacher } & \text { 5ducation, }\end{array}$ https://files.eric.ed.gov/fulltext/EJ834086.pdf

14. Eid, M. I., \& Al-Jabri, I. M. (2016). Social networking, knowledge sharing, and student learning: The case of university students. Computers \& Education, 99, 14-27. http://iranarze.ir/wp-content/uploads/2016/12/E3153.pdf

15. Gon, S., \& Rawekar, A. (2017). Effectivity of e-learning through WhatsApp as a teaching learning tool. MVP Journal of Medical Science, 4(1), 19-25. http://www.informaticsjournals.com/index.php/mvpims/article/view/8454

16. Hamade, S. N. (2013). Perception and use of social networking sites among university $\quad$ students. Library Review, 62(6-7), 388-397. https://www.emerald.com/insight/content/doi/10.1108/LR-12-2012-0131/full/html

17. Jin, Y., Liu, B. F., \& Austin, L. L. (2014). Examining the role of social media in effective crisis management: The effects of crisis origin, information form, and source on publics' crisis responses. Communication Research,41(1), 74-94. https://journals.sagepub.com/doi/10.1177/0093650211423918

18. Karpinski, A. C., Kirschner, P. A., Ozer, I., Mellott, J. A., \& Ochwo, P. (2013). An exploration of social networking site use, multitasking, and academic performance among United States and European university students. Computers in Human 


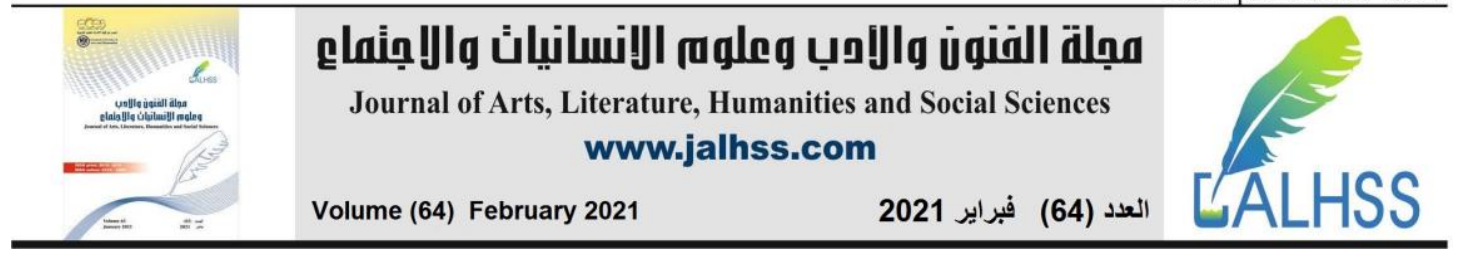

Behavior, 29(3),

1182-1192. https://www.sciencedirect.com/science/article/abs/pii/S0747563212002798?via\%3Di $\underline{\text { hub }}$

19. Khatun, A., \& Al-Dhlan, K. A. (2017). Effectiveness of WhatsApp: A Social Media Tool for Student's Activities in Saudi Arabia. International Journal of Technology and Educational Marketing (IJTEM), 7(2), 17-23. https://www.igiglobal.com/viewtitlesample.aspx?id=191226\&ptid=158678\&t=effectiveness + of + what sapp:+a+social+media+tool+for+student $\% 27 \mathrm{~s}+$ activities+in+saudi+arabia

20. Lauricella, S., \& Kay, R. (2013). Exploring the use of text and instant messaging in higher education classrooms. Research in Learning Technology, 21. https://journal.alt.ac.uk/index.php/rlt/article/view/1345/pdf_1

21. Lenhart, A., Madden, M., Smith, A., \& Macgill, A. (2007). Teens and Social Media. https://www.pewresearch.org/internet/2007/12/19/teens-and-social-media/

22. Malka, V., Ariel, Y., \& Avidar, R. (2015). Fighting, worrying and sharing: Operation 'Protective Edge'as the first WhatsApp war. Media, War \& Conflict, 8(3), 329-344. https://journals.sagepub.com/doi/full/10.1177/1750635215611610

23. Malecela, I. O. (2016). Usage of Whatsapp among postgraduate students of Kulliyyah of Education, International Islamic University Malaysia. International Journal of Advanced Engineering Research and Science,3(10), 236879. https://ijaers.com/uploads/issue_files/21\%20IJAERS-AUG-2016-19-

Usage \%20of\%20Whatsapp \%20among\%20Postgraduate\%20Students $\% 20$ of $\% 20 \mathrm{Kulli}$ yyah\%20of\%20Education, \%20International\%20Islamic\%20University\%20Malaysia. $\underline{\mathrm{pdf}}$

24. Rambe, P., \& Bere, A. (2013). Using mobile instant messaging to leverage learner participation and transform pedagogy at a South African University of Technology. British Journal of Educational Technology, 44(4), 544-561. https://berajournals.onlinelibrary.wiley.com/doi/abs/10.1111/bjet.12057

25. Raza, S. A., Qazi, W., \& Umer, A. (2017). Facebook is a source of social capital building among university students: evidence from a developing country. Journal of Educational Computing Research, 55(3), https://journals.sagepub.com/doi/10.1177/0735633116667357

26. Reeves, A. J., Alkhalaf, S., \& A., M. (2019). WhatsApp as an educational support tool in a Saudi university. International Journal of Advanced Computer Science and Applications, 10(8),

394-401.

https://www.researchgate.net/profile/Ahmad_Reeves/publication/335694357_WhatsA pp_as_an_Educational_Support_Tool_in_a_Saudi_University/links/5d79eaa7a6fdcc9 961c12fa4/WhatsApp-as-an-Educational-Support-Tool-in-a-Saudi-University.pdf 27. Rosenberg, H. (2016). Media, teens \& children: Consumption, habits and social practices. In: R. Mann \& A. Lev-On (Eds.), Annual report: The Israeli media in 2015: Agendas, uses and trends (pp. 70-91). Ariel: New Media Research Institute, Ariel University.

28. Saudi Arabia social media statistics 2020. (2020, September 8). Retrieved November 15, 2020, from https://www.globalmediainsight.com/blog/saudi-arabiasocial-media-statistics/ 


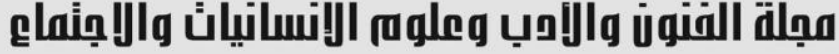

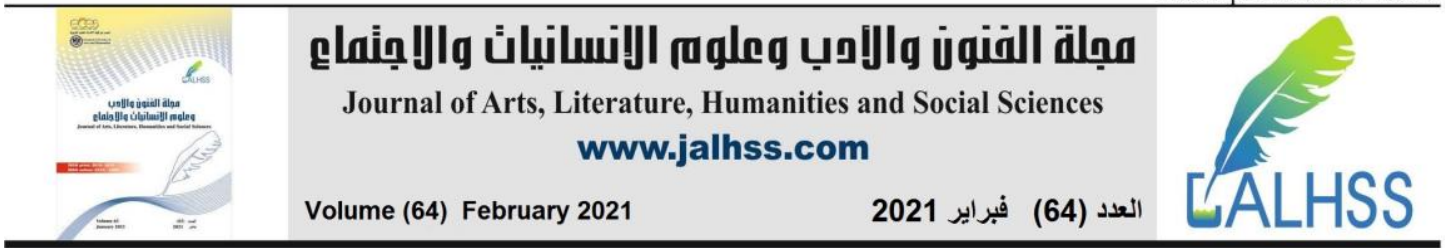

29. Smit, I. (2012). WhatsApp with BlackBerry: Can messengers (BBM) be MXit? Paper presented at the 14th Annual Conference on World Wide Web Applications. Cape Peninsula University of Technology, Cape Town, South Africa.

30. Sweeny, S. M. (2010). Writing for the instant messaging and text messaging generation: Using new literacies to support writing instruction. Journal of Adolescent \& Adult Literacy, 54(2), 121-130. https://ila.onlinelibrary.wiley.com/doi/abs/10.1598/JAAL.54.2.4

31. van Rensburg, A., Conradie, D. P., \& Dondolo, H. B. (2017). The use of the situational crisis communication theory to study crisis response strategies at a university of technology. Communitas, 22,

62-74. https://journals.ufs.ac.za/index.php/com/article/view/3293/3166 32. Vorderer, P., Krömer, N., \& Schneider, F. M. (2016). Permanently onlinepermanently connected: Explorations into university students' use of social media and mobile smart devices. Computers in Human Behavior, 63, 694-703. https://www.sciencedirect.com/science/article/abs/pii/S0747563216304216?via\%3Di $\underline{\text { hub }}$ 


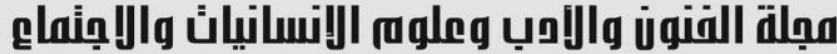

Journal of Arts, Literature, Humanities and Social Sciences

www.jalhss.com

Volume (64) February 2021

العدد (64) فبراير 2021

\section{Appendix 1: Study Questionnaire}

\section{Factors driving Saudi Arabian students to use WhatsApp}

1. Do you use the WhatsApp application in university affairs? If yes, what exactly do you use it for?

2. Do you use WhatsApp more than other digital communication methods (such as emails) when communicating with classmates and professors, etc. at university? If yes, please indicate the reasons for which you prefer to use it rather than other electronic communication channels.

3. How widespread is the use of WhatsApp among students at the university for education and communication?

\section{Advantages and disadvantages of using WhatsApp}

4. In your opinion, what are the advantages of using WhatsApp compared to other means of electronic communication in your communication with your colleagues, students, professors, etc. at the university?"

5. In your opinion, what are the negative effects resulting from your use of WhatsApp that have impacted your learning process at the university?

The extent to which students believe that WhatsApp impacts the quality of their university education

6. In your opinion, how has use of WhatsApp affected the quality of education at the university? 